Original Research Article

\title{
Treatment satisfaction and safety of sitagliptin versus pioglitazone in patients with type 2 diabetes mellitus inadequately controlled on metformin monotherapy
}

\author{
Shahnaz Haque ${ }^{1 *}$, Anand Shukla ${ }^{1}$, Anil Kem²
}

\begin{abstract}
${ }^{1}$ Department of Pharmacology, ${ }^{2}$ Department of Medicine, Saraswathi Institute of Medical Sciences (SIMS), Hapur, Uttar Pradesh, India
\end{abstract}

Received: 29 November 2016 Accepted: 26 December 2016

*Correspondence to:

Dr. Shahnaz Haque,

Email:

shahnazhaque89@gmail.com

Copyright: () the author(s), publisher and licensee Medip Academy. This is an openaccess article distributed under the terms of the Creative Commons Attribution NonCommercial License, which permits unrestricted noncommercial use, distribution, and reproduction in any medium, provided the original work is properly cited.

\begin{abstract}
Background: This study was designed to assess the treatment satisfaction between Sitagliptin versus Pioglitazone added to Metformin in patients with type 2 diabetes mellitus (T2DM).

Methods: We conducted a prospective, open label, randomized, parallel group study in SIMS, Hapur, U. P. Eligible patients fulfilling inclusion criteria were randomized into two groups having 25 patients in each group using tab Sitagliptin 100mg,tab Pioglitazone 30mg added to ongoing tab Metformin (500mg) therapy for 16 weeks. The follow-up visits were on weeks 4,12 and 16.

Results: 16 weeks later, addition of Sitagliptin 100mg compared to that of Pioglitazone $30 \mathrm{mg}$ to ongoing Metformin therapy provided similar glycosylated haemoglobin (HbA1c) lowering efficacy in patients with T2DM with inadequate glycemic control on metformin monotherapy. Change in $\mathrm{HbA} 1 \mathrm{c}$ in group1 was $-0.656 \pm 0.21 \%(\mathrm{p}<0.0001)$ whereas in group 2 was $-0.748 \pm 0.35 \%$ $(\mathrm{p}<0.0001)$. Hence decrease in HbA1c from baseline was more in group2.Both treatments were well tolerated with negligible risk of hypoglycaemia. Weight loss was observed with Sitagliptin in contrast to weight gain seen in Pioglitazone.

Conclusions: In this study, Sitagliptin $100 \mathrm{mg}$ along with metformin therapy in comparison to pioglitazone $30 \mathrm{mg}$ plus metformin therapy was effective, welltolerated and improved glycemic control in both the groups. Addition of pioglitazone had cause oedema and weight gain to the patients whereas sitagliptin caused weight loss in its patients.
\end{abstract}

Keywords: Metformin, Pioglitazone, Sitagliptin, Type 2 diabetes mellitus

\section{INTRODUCTION}

Diabetes mellitus is a chronic metabolic disease affecting millions worldwide. Long-standing diabetes mellitus is associated with an increased prevalence of microvascular and macrovascular diseases. Based on a compilation of studies from different parts of the world, the World Health Organization (WHO) has projected that in near future, the maximum increase in diabetes would occur in India.

Oral hypoglycemic agents are prescribed if lifestyle measures alone fail to control disease progression. Metformin is the most commonly prescribed first-line antidiabetes drug worldwide, but due to the progressive worsening of blood glucose control during the natural history of T2DM, combination therapy usually becomes necessary. ${ }^{1}$ The thiazolidinedione (TZD) pioglitazone, is a peroxisome proliferator activated receptor agonist that reduces insulin resistance by enhancing the action of insulin, thereby promoting glucose utilization in peripheral tissues, suppressing gluconeogenesis, and reducing lipolysis. It is commonly prescribed in combination with metformin when the later fails to 
control blood glucose alone. The efficacy of pioglitazone plus metformin combination therapy has been proven in such patients in several randomized, placebo or active comparator-controlled trials of up to 3.5 years duration. ${ }^{2}$

Sitagliptin is an oral, once-daily, potent, and highly selective dipeptidylpeptidase- 4 (DPP-4) inhibitor for the treatment of T2DM. DPP-4 inhibitors enhance levels of active incretin hormones- Glucagon like peptide-1 (GLP1) and glucose dependent insulinotropic peptide (GIP), gut-derived peptides that are released into the circulation after ingestion of a meal. In the presence of elevated glucose concentrations, GLP-1 and GIP increase insulin release and GLP-1 lowers glucagon secretion, thereby decreasing the postmeal rise in glucose concentration and reducing fasting glucose concentrati6ns. ${ }^{3}$ Both GLP-1. and GIP are rapidly inactivated by the enzyme DPP-4. By blocking this inactivation, DPP-4 inhibitors increase active incretin levels, enhancing incretin effects, and thereby offer a new therapeutic approach for the management of patients with T2DM. Sitagliptin is approved both as monotherapy and as add on to existing first line antidiabetic agents like metformin.

Treatment satisfaction was assessed using the DTSQ (both status version and change version) which is an eight-item questionnaire. The Treatment Satisfaction score is the sum of six of the items of the DTSQ for each respondent. The additional two items measure perceived frequency of hyperglycemia and hypoglycemia and are considered separately. ${ }^{4}$

\section{METHODS}

This was a prospective, open-label, randomized, parallel group study conducted in the Department of Pharmacology, Department of Medicine, SIMS, Hapur, U.P. The study was done for 16 weeks during a period of December 2014 to April 2015. During this period, a total of 94 patients were screened. Of these 42 patients were excluded because of exclusion and inclusion criteria. Of the 52 patients who entered the study, 2 were lost to follow up. Later on, these 50 patients were randomized into two groups (Figure 1).

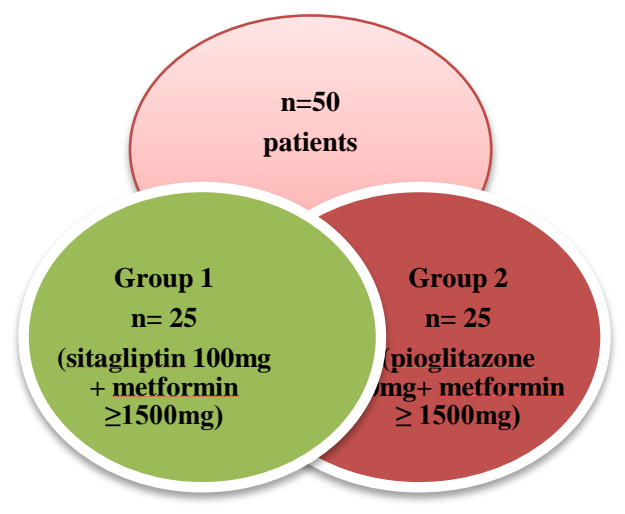

Figure 1: Randomization of the two groups.
The study was approved by the Institutional Ethics Committee. Written informed consent was obtained from all the subjects before their enrollment in the study. The follow up visits were on weeks 4,12 and 16.

\section{Inclusion criteria}

Patients of either sex aged $\geq 18$ yrs with type 2 Diabetes Mellitus/ Patients who are on metformin monotherapy $(\geq 1500 \mathrm{mg} /$ day) for at least 1 month/ Glycosylated Hemoglobin (HbA1c) $7.5 \%$ to $11 \%$ / Fasting plasma glucose $(\mathrm{FPG}) \geq 140 \mathrm{mg} / \mathrm{dl}$.

\section{Exclusion criteria}

Type 1 Diabetes Mellitus /Acute metabolic diabetic complications within past 6 months/ FPG >270mg/dl / $\mathrm{HbA} 1 \mathrm{c}>11 \%$.

\section{Scoring of DTSQ questionnaire}

The questionnaire is filled by the patient on his/her own after making sure that the patient has understood what he has to do. The numbers encircled by patients for six of the eight items are summed to produce a measure of satisfaction with treatment. Items to be summed are 1, 4, $5,6,7$, and 8. Scores in DTSQs can range from 0 (very dissatisfied) to 36 (very satisfied). Remaining two items i.e. items 2 and 3 are treated individually. Item 2 provides an indication for perception of hyperglycemia and item 3 provides an indication for perception of hypoglycemia on a scale ranging from 0 "None of the time" to 6 "Most of the time".Treatment satisfaction scores in DTSQc range potentially from -18 to +18 .

\section{Statistical analysis}

All the parameters were analyzed by using computer software SPSS 16.0 version. $\mathrm{P}$ value of $<0.05$ was considered significant.

\section{RESULTS}

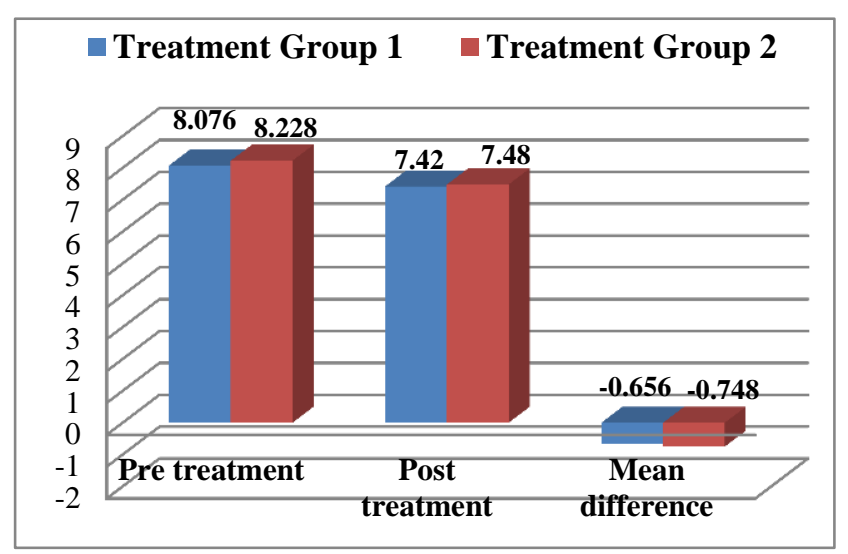

Figure 2: Comparison of HbA1c levels in treatment groups at baseline and at end of study. 
The Group 1 and Group 2 had similar baseline HbA1c levels $(8.076 \pm 0.722$ and $8.228 \pm 0.822$, respectively). After 16 weeks, both the groups had a significant decrease in HbA1c- from baseline to end in Group1 was $0.656 \pm 0.21 \%(\mathrm{p}<0.0001)$ whereas it was $-0.748 \pm$ $0.35 \%$ ( $\mathrm{p}<0.0001$ ) in Group 2 (Figure 2). Hence, the decrease in HbA1c from baseline was more in Group2, but the difference between the change produced in the two groups was not statistically significant $(\mathrm{p}=0.268)$.

\section{Adverse effects}

A total of 7 patients in the study population reported adverse events.

Table 1: Adverse events in the two groups.

\begin{tabular}{|lll|}
\hline Adverse event & $\begin{array}{l}\text { No. of patients reporting } \\
\text { adverse event }\end{array}$ \\
\hline Group 1 & Group 2 \\
\hline Headache & 1 & 2 \\
\hline Diarrhea & 1 & 0 \\
\hline Nausea, Vomiting & 1 & 0 \\
\hline Oedema & 0 & 2 \\
\hline
\end{tabular}

No severe adverse event was seen throughout the study. There was no episode of hypoglycemia reported by any patient of either group during the study period.

\section{Weight}

After the study period, a mean decrease of $0.58 \mathrm{kgs}$ was seen in treatment Group1 from a baseline mean weight of $72.1 \pm 13.76 \mathrm{kgs}$ and this change was statistically significant $(\mathrm{p}<0.01)$ (Figure 3 and 4$)$.

In contrast to this, subjects of Group2 had a mean increase of $0.90 \mathrm{kgs}$ in their weight from a baseline level of $72.68 \pm 10.83 \mathrm{kgs}$. This increase of weight was also statistically significant ( $\mathrm{p}=0.001)$ (Figure 3 and 4$)$.

While comparing the two groups with respect to their effect on weight, there was a statistically significant difference of $1.48 \mathrm{kgs}$ in the mean weight change produced in the two treatment groups.

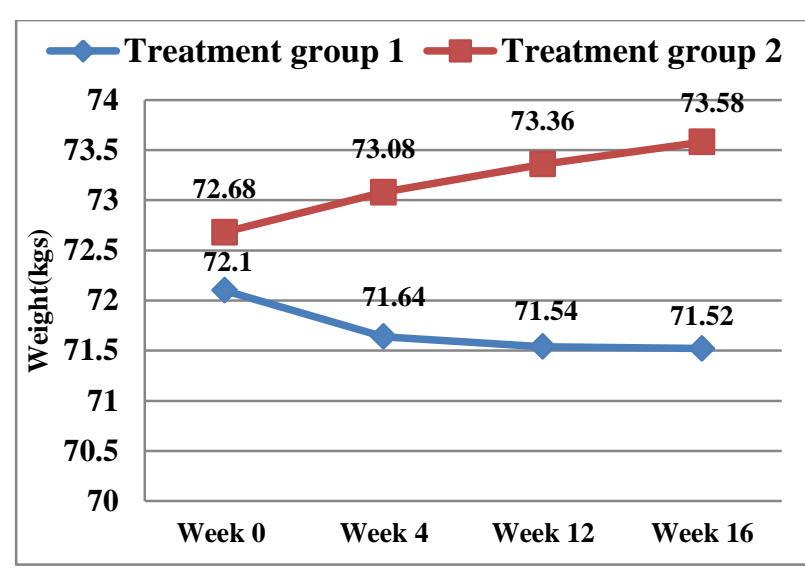

Figure 3: Comparative mean weight in both groups.

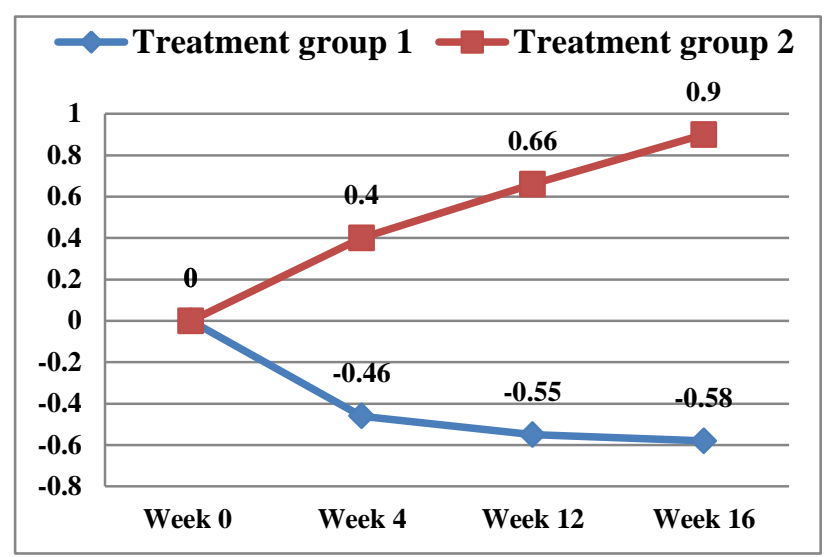

Figure 4: Comparative mean weight change in both groups.

\section{Treatment satisfaction}

As evaluated through the Diabetes Treatment Satisfaction Questionnaire (DTSQs and DTSQc), there was a significant improvement in the treatment satisfaction in both the groups at the end of the study as compared to the treatment satisfaction before beginning add-on therapy ( $<<0.001$ for total score improvement in both groups). The improvement in the treatment satisfaction was more in the patients of treatment group 1 but this difference was not statistically significant from treatment group 2 .

Table 2: Comparison of mean difference in treatment satisfaction (DTSQ score) in the two treatment groups.

\begin{tabular}{|lllllll|}
\hline Week & $\begin{array}{l}\text { Change } \\
\end{array}$ & Group 1 & Group 2 & Difference b/w change in two groups & t-value & p-value between two groups \\
\hline 4 v/s 0 & $5.60 \pm 4.81$ & $5.24 \pm 4.99$ & $-0.36(95 \%$ CI: -3.18 to 2.46$)$ & 0.256 & 0.798 \\
\hline 16 v/s 4 & $1.92 \pm 3.59$ & $0.68 \pm 4.3$ & $-1.24(95 \%$ CI: -4.09 to 0.89$)$ & 1.025 & 0.31 \\
\hline 16 v/s 0 & $7.52 \pm 3.64$ & $5.92 \pm 5.01$ & $-1.6(95 \%$ CI: -4.09 to 0.89$)$ & 1.28 & 0.203 \\
\hline
\end{tabular}

Also, the DTSQc score at week 16 was positive in both groups, suggesting an increase in treatment satisfaction in both groups. Similar to the change in DTSQs, DTSQc was higher in treatment group1 than in group 2 (6.96 and 6.68 respectively), but this difference between the two groups was not significant $(\mathrm{p}=0.85)$. 


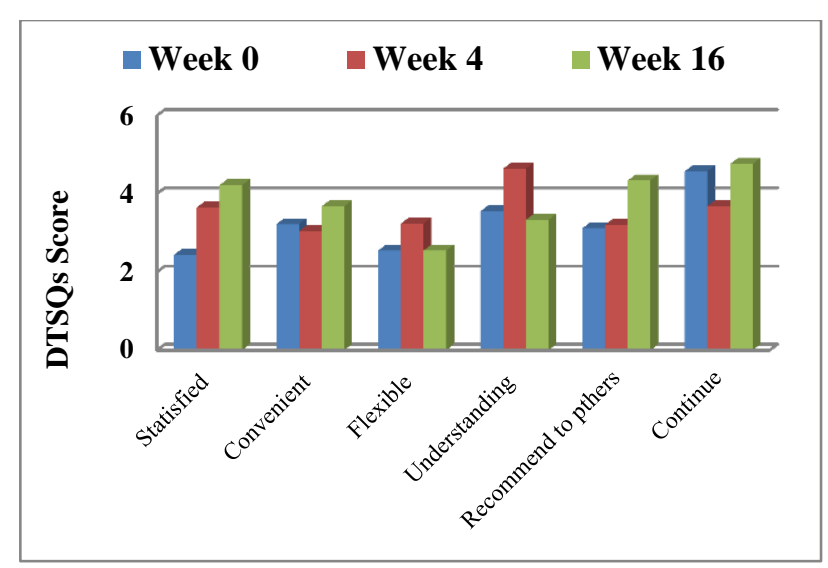

Figure 5: Treatment satisfaction in Sitagliptin+ Metformin group.

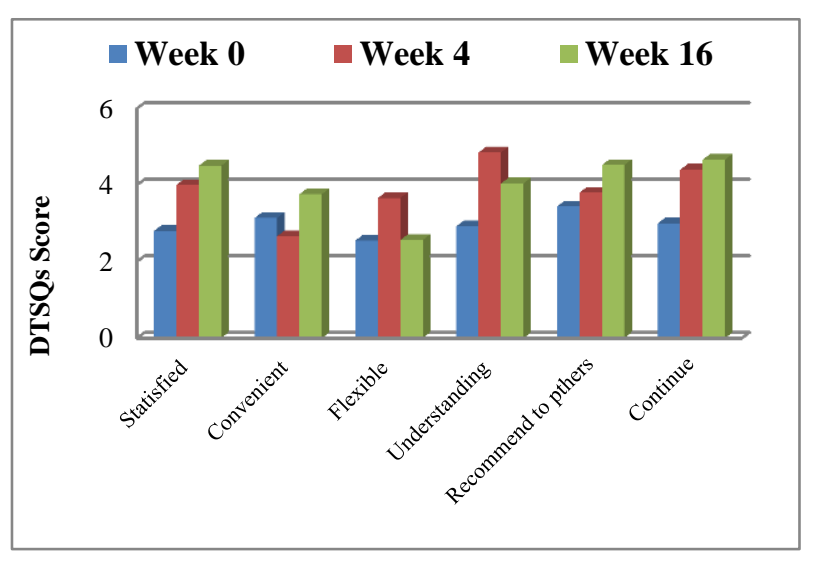

Figure 6: Treatment satisfaction in Pioglitazone+ Metformin group.

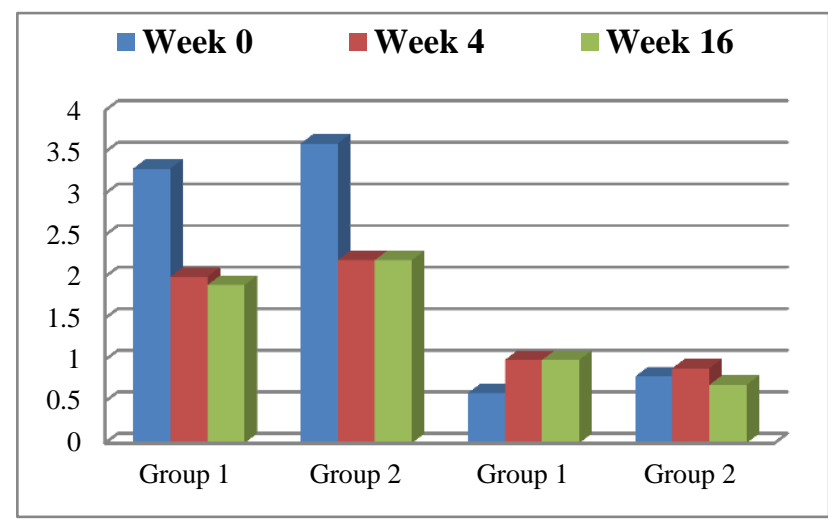

Figure 7: Perceived frequency of hyper and hypoglycemia in the two groups.

As evident from Figure 7, there was a significant fall in the perceived frequency of hyperglycemia (Ques no.2 in DTSQ) in both the treatment groups from week 4 onwards and the two groups did not differ in this regard.

There was no significant change in the perceived frequency of hypoglycemia (Ques No.3 in DTSQ) in either group.

\section{DISCUSSION}

T2DM is a progressive disease characterized by worsening glycemia; higher doses and additional medications are required over a period of time to meet treatment goals. Every year, approximately 5-10\% of patients treated with a sulphonylurea or metformin monotherapy experience 'secondary failure'. 5 Thus, more than one medication will be necessary for the majority of patients over time.

Metformin is recommended as the initial pharmacological therapy, in the absence of any contraindications, due to its favorable effect on glycemic control, absence of weight gain or hypoglycemia, generally low level of side effects, high level of acceptance, and relatively low cost. ${ }^{6}$ In spite of its beneficial effects in improving glycemic control, very often, metformin alone is insufficient for achievement of good metabolic control. This necessitates addition of another OHA to metformin. ${ }^{7}$

In the present study, there was a significant decrease in $\mathrm{HbA}_{1 \mathrm{c}}$ in both the treatment groups from baseline to week 16. The decrease was more with pioglitazone $(0.748 \%)$ than sitagliptin $(0.656 \%)$. But the difference between the two groups was not significant and based on a prespecified margin, sitagliptin was found to be non-inferior to pioglitazone.

The reduction in $\mathrm{HbA} 1 \mathrm{c}$ seen in our study with sitagliptin added to metformin was $0.656 \%$. It was found to be in tune with other studies of sitagliptin combined with metformin done by Charbonnel et al and Hermansen et al who observed a reduction of $0.7 \%$ and $0.74 \%$ respectively. ${ }^{8,9}$ Both these studies were of 24 weeks duration.

A 16 week study of a combination of pioglitazone with metformin done by Einhorn et al has shown a HbA1C reduction of $0.7 \%$ which is consistent with the reduction of $0.748 \%$ seen in our study. ${ }^{10,11}$ However, such reduction was more in similar studies but with a longer duration (Bolli et al, $0.9 \%, 24$ weeks; Matthews et al, 1\% 52 weeks). ${ }^{12,13}$

A significant and progressive weight gain was seen with pioglitazone on every visit. Whereas, weight decreased in the sitagliptin group during the first 4 weeks of treatment and then remained almost stable; with a slight trend toward further reduction over the subsequent treatment period (total $0.56 \mathrm{kgs}$ mean weight loss at week 16).

Based on the results from other studies in combination with metformin, sitagliptin appears to be largely weight neutral with results varying from weight gain observed by Hermansen et al ( 24 wks, $+0.8 \mathrm{~kg}$ ), no effect on body weight as seen by Raz et al (30 wks, no effect) to body weight reduction studied by Scott et al (18 wks, $-0.4 \mathrm{~kg})$ and Nauck et al (52 wks, $-1.5 \mathrm{kgs}){ }^{9,14-16}$ 
In patients receiving pioglitazone in our study, body weight increased progressively on each visit to a total mean increase of $0.9 \mathrm{kgs}$ at week 16. The increase in mean body weight in patients treated with pioglitazone was less than that in previous reports by Bolli et al (24 wks study, $1.9 \mathrm{kgs}$ ), Einhorn et al (16 wks study, 0.95 $\mathrm{kgs})$ and Urnpierrez et al (28 wks study, $1.74 \mathrm{kgs}){ }^{12,17,18}$

In the present study, both the treatments were well tolerated and were not associated with treatment-related serious adverse events. In our study, mild headache, diarrhea and vomiting were reported by three patients in the sitagliptin group which were managed symptomatically. Such adverse effects have already been reported in previous studies with sitaglipin. ${ }^{8,16,19}$

In our study, oedema and weight gain were the most common adverse events in the pioglitazone group and these have also been reported previously with pioglitazone, both as monotherapy and as combination with metformin. ${ }^{13,18,20}$ Edema has been linked to the precipitation of cardiac failure. ${ }^{21}$ In tune with previous reports the severity of oedema in our study was recorded as mild. ${ }^{17,18}$

Treatment satisfaction scores from the DTSQs and DTSQc filled pre and post-treatment revealed that the treatment satisfaction for both the treatment groups using sitagliptin or pioglitazone in combination to metformin was significantly more. There were significant improvements in all the parameters of DTSQ questionnaire. There was no significant difference in the improvement in treatment satisfaction produced in the two groups though this was more with sitagliptin.

\section{CONCLUSION}

In this study, Sitagliptin 100mg along with Metformin therapy in comparison to Pioglitazone $30 \mathrm{mg}$ plus Metformin therapy was effective, well tolerated and improved glycemic control with negligible risk of hypoglycemia. Addition of Pioglitazone had cause oedema and weight gain to the patients whereas Sitagliptin caused weight loss in its patients.

Funding: No funding sources

Conflict of interest: None declared

Ethical approval: The study was approved by the Institutional Ethics Committee

\section{REFERENCES}

1. Turner RC, Cull CA, Frighi V, Holman RR. Glycemic control with diet, sulfonylurea, metformin, or insulin in patients with type 2 diabetes mellitus: progressive requirement for multiple therapies (UKPDS 49). JAMA. 1999;281:2005-12.

2. Deeks ED, Scott LJ. Pioglitazone/Metformin. Drugs. 2006;66(14):1863-77.
3. Gallwitz B. Review of sitagliptin phosphate: a novel treatment for T2DM. Vasc Health Risk Manag. 2007;3(2):203-10.

4. Bradley C, Lewis K. Measures of psychological wellbeing and treatment satisfaction developed from the responses of people with tablet-treated diabetes. Diabet Med. 1990;7:445-51.

5. Matthews DR, Cull CA, Stratton IM, Holman RR, Turner RC, UK Prospective Diabetes Study (UKPDS) Group. UKPDS 26: sulphonylurea failure in non-insulin dependent diabetic patients over six years. Diabet Med. 1998;15:297-303.

6. Nathan OM, Buse Ill, Davidson MB, Ferrannini E, Rury RH, Sherwin R et al. Medical Management of Hyperglycemia in Type 2 Diabetes: A Consensus Algorithm for the Initiation and Adjustment of Therapy: A consensus statement of the American Diabetes Association and the European Association for the Study of Diabetes. Diabetes Care. 2009;32(1):193-203.

7. Bo Ahren. Novel combination treatment of type 2 diabetes DPP-4 inhibition + metformin Vascular Health and Risk Management. 2008;4(2):383-94.

8. Charbonnel B, Karasik A, Liu J, Wu M, Meininger G. For the sitagliptin study 020 group* Efficacy and Safety of the Dipeptidyl Peptidase-4 Inhibitor Sitagliptin Added to Ongoing Metformin Therapy in Patients With Type 2 Diabetes Inadequately Controlled with Metformin Alone. Diabetes Care. 2006;29:2638-43.

9. Hermansen K, Stein PP, Thornberry NA. Efficacy and safety of the DPP-4 inhibitor, sitagliptin, in patients with type 2 diabetes mellitus inadequately controlled on glimiperide alone or on glimiperide and metformin. Diabetes obes Metab. 2007;9:733-45.

10. Yki-Jarvinen H. Drug therapy. Thiazolidinediones. N Engl J Med. 2004;351:1106.

11. Green BD, Flatt PR, Bailey CJ. Dipeptidyl peptidase IV (DPP IV) inhibitors: a newly emerging drug class for the treatment of type 2 diabetes. Diabetes Vas Dis Res. 2006;3(3):159-65.

12. Bolli G, Dotta F, Rochotte E, Cohen SE. Efficacy and tolerability of vildagliptin vs. pioglitazone when added tometformin:a 24-week, randomized, doubleblind study. Diabetes Obes Metab. 2008;10:82-90.

13. Matthews DR, Charbonnel BH, Hanefeld M. Longterm therapy with addition of pioglitazone to metformin compared with the addition of gliclazide to metformin in patients with type 2 diabetes: a randomized, comparative study. Diabetes Metab Res Rev. 2005;21(2):167-74.

14. Raz I, Chen Y, Wu M, Hussain S, Kaufman KD, Amatruda JM et al. Efficacy and safety of sitagliptin added to ongoing metformin therapy in patients with type 2 diabetes. Cur Med Res Opin. 2008;24(2):53750 .

15. Scott R, Loeys T, Davies MJ, Engel SS. Efficacy and safety of sitagliptin when added to ongoing metformin therapy in patient's with type 2 diabetes, Diabetes Obes Metab. 2008;10(10):959-69. 
16. Nauck MA, Meininger G, Sheng D, Terranella L, Stein PP for the Sitagliptin Study 074 Qroup. Efficacy and safety of the dipeptidyl peptidase-4 inhibitor, sitagliptin, compared with the sulfonylurea, glipizide, in patients with type 2 diabetes inadequately controlled on metformin alone: a randomized, double-blind, non-inferiority trial. Diabetes Obes Metab. 2007;9:194-205.

17. Einhorn D, Rendell M, Rosnezweig J. Pioglitazone hydrochloride in combination with metformin in the treatment of T2DM mellitus: a randomized, placebocontrolled study. Clin Ther. 2000;22:1395-409.

18. Umpierrez G, Issa M, Vlajnic A. Glimepiride versus pioglitazone combination therapy in subjects with type 2 diabetes inadequately controlled. 011 metformin monotherapy: results of a randomized clinical trial. Curr Med Res Opin. 2006;22:751-9.

19. Goldstein BJ, Feinglos MN, Lunceford JK, Johnson J, Herman DW. For the Sitagliptin 036 Study Group.
Effect of Initial Combination Therapy with Sitagliptin, a Dipeptidyl Peptidase-4 Inhibitor, and Metformin on Glycemic Control in Patients with T2DM. Diabetes Care. 2007;30(8):1979-87.

20. Rosenstock J, Baron MA, Camisasca RP. Efficacy and tolerability of initial combination therapy with vildagliptin and pioglitazone compared to component monotherapy in patients with type 2 diabetes. Diabetes Obes Metab. 2007;9:175-85.

21. Lawrence JM, Reckles PD. Pioglitazone. Int J Clin Pract. 2000;54:614-8.

Cite this article as: Haque S, Shukla A, Kem A.

Treatment satisfaction and safety of sitagliptin versus pioglitazone in patients with type 2 diabetes mellitus inadequately controlled on metformin monotherapy. Int J Basic Clin Pharmacol 2017;6:338-43. 